\title{
Spared and Impaired Spoken Discourse Processing in Schizophrenia: Effects of Local and Global Language Context
}

\author{
Tamara Y. Swaab, ${ }^{1 \star}$ Megan A. Boudewyn, ${ }^{1 \star}$ Debra L. Long, ${ }^{1}$ Steve J. Luck, ${ }^{1}$ Ann M. Kring, ${ }^{2}$ J. Daniel Ragland, ${ }^{1}$ \\ Charan Ranganath, ${ }^{1}$ Tyler Lesh, ${ }^{1}$ Tara Niendam, ${ }^{1}$ Marjorie Solomon, ${ }^{1}$ George R. Mangun, ${ }^{1}$ and Cameron S. Carter ${ }^{1}$ \\ ${ }^{1}$ University of California, Davis, Davis, California 95616, and ${ }^{2}$ University of California, Berkeley, Berkeley, California 94720
}

Individuals with schizophrenia are impaired in a broad range of cognitive functions, including impairments in the controlled maintenance of context-relevant information. In this study, we used ERPs in human subjects to examine whether impairments in the controlled maintenance of spoken discourse context in schizophrenia lead to overreliance on local associations among the meanings of individual words. Healthy controls $(n=22)$ and patients $(n=22)$ listened to short stories in which we manipulated global discourse congruence and local priming. The target word in the last sentence of each story was globally congruent or incongruent and locally associated or unassociated. ERP local association effects did not significantly differ between control participants and schizophrenia patients. However, in contrast to controls, patients only showed effects of discourse congruence when targets were primed by a word in the local context. When patients had to use discourse context in the absence of local priming, they showed impaired brain responses to the target. Our findings indicate that schizophrenia patients are impaired during discourse comprehension when demands on controlled maintenance of context are high. We further found that ERP measures of increased reliance on local priming predicted reduced social functioning, suggesting that alterations in the neural mechanisms underlying discourse comprehension have functional consequences in the illness.

\section{Introduction}

Language abnormalities, including deficits in comprehension, are among the most salient cognitive deficits in schizophrenia. A fundamental question is whether these abnormalities mainly reflect deficits in relatively low-level linguistic functions (e.g., lexical access) or whether they reflect deficits in higher-level comprehension processes that rely on the controlled maintenance of context relevant information in working memory (Cohen et al., 1999). Language disorders in schizophrenia may be related to impairments in the buildup of context, especially when integration demands are high, as is the case during discourse comprehension (Kuperberg et al., 2008a). Indeed, communication deficits typically manifest at the level of discourse rather than at the level of individual words or sentences (Hoffmann et al., 1986; Docherty et al., 1998), yet very few studies have examined discourse processing in schizophrenia under controlled experimental conditions (Ditman and Kuperberg, 2007). Thus far, the results of these studies suggest that patients have deficits in their ability to benefit from language context (Gernsbacher et al., 1999; Kuperberg, 2010a,b; Boudewyn et al., 2012a).

\footnotetext{
Received March 2, 2013; revised Aug. 16, 2013; accepted Aug. 19, 2013

Author contributions: T.Y.S., M.A.B., D.L.L., S.J.L., A.M.K., J.D.R., C.R., T.L., T.N., M.S., G.R.M., and C.S.C. designed research;M.A.B., T.L., and T.N. performed research; T.Y.S. and M.A.B. analyzed data; T.Y.S., M.A.B., and C.S.C. wrote the paper.

The research reported in this paper was supported by NIMH Grant 1R24MH081807 (principle investigator:C.S.C.). We thank Shaun Rafael and Tara Miskovitch for their assistance in data collection.

*T.Y.S. and M.A.B. contributed equally to this manuscript.

The authors declare no competing financial interests.

Correspondence should be addressed to Tamara Y. Swaab, Department of Psychology and Center for Mind and Brain, One Shields Avenue, Davis, CA 95616. E-mail: swaab@ucdavis.edu.

DOI:10.1523/JNEUROSCI.0965-13.2013

Copyright $\odot 2013$ the authors $\quad 0270-6474 / 13 / 3315578-10 \$ 15.00 / 0$
}

In contrast to deficits in contextual processing, schizophrenia patients have shown intact or amplified effects of associative relations between words in a two-word priming paradigm (Manschreck et al., 1988; Spitzer et al., 1993; Barch et al., 1996), when priming does not depend on controlled strategic processes induced by task demands (Kreher et al., 2009). In addition, there is evidence for increased sensitivity to lexical associations when the demands of maintaining the language context are higher, as in discourse comprehension (Ditman et al., 2011).

In electrophysiological studies of healthy participants, sensitivity to global discourse coherence and local meaning associations is reflected by a modulation of the N400, an ERP that is sensitive to semantic aspects of linguistic input (Swaab et al., 2012). Specifically, in studies that have manipulated global coherence and local association in the same experiment, we have shown that the amplitude of the N400 is reduced to both words that are coherent with preceding discourse context compared with words that are not and words associated with meaning to a preceding word in the local context compared with words that are not (Boudewyn et al., 2012b,c).

In the current study, we used ERPs to measure the effects of manipulations of global discourse coherence and local associative relations between words within the same paradigm (see Table 2). We predicted that effects of discourse coherence would be attenuated in schizophrenia patients (relative to healthy controls), because discourse comprehension produces additional demands on the controlled maintenance of context-relevant information, which relies on prefrontally mediated cognitive control operations that are impaired in schizophrenia (MacDonald et al., 2005; Lesh et al., 2011). In contrast, we predicted that schizophrenia patients would show an increased reliance on local lexical associ- 


\begin{tabular}{|c|c|c|}
\hline & $\begin{array}{l}\text { Healthy controls } \\
(n=22)(\text { mean } \pm \text { SD) }\end{array}$ & $\begin{array}{l}\text { Schizophrenia patients } \\
(n=22)(\text { mean } \pm \text { SD) }\end{array}$ \\
\hline Age & $22.5 \pm 4.4$ & $24.3 \pm 5.2$ \\
\hline Participant education (years) & $14.6 \pm 1.4$ & $13 \pm 1.5$ \\
\hline Parent education (years) & $15.2 \pm 2.4$ & $15.4 \pm 2.6$ \\
\hline \multicolumn{3}{|l|}{ Symptom severity } \\
\hline BPRS & & $41.4 \pm 10.6$ \\
\hline SAPS & & $13.9 \pm 15.1$ \\
\hline SANS & & $32.1 \pm 14.4$ \\
\hline Disorganization (maximum 36) & & $6.1 \pm 2.8$ \\
\hline Positive (maximum 38) & & $10.5 \pm 6.8$ \\
\hline Negative (maximum 41) & & $14 \pm 5.6$ \\
\hline \multicolumn{3}{|l|}{ Functional characteristics } \\
\hline GAF (maximum 100) & & $49.1 \pm 9.7$ \\
\hline Social & & $5.4 \pm 1.6$ \\
\hline Role & & $4.2 \pm 2.9$ \\
\hline
\end{tabular}

ations among words. We used naturally produced spoken discourse to make a link with real-world comprehension demands and daily functioning in schizophrenia. We further examined whether abnormal processing of global discourse context and local associative relations were correlated with impairments in social and occupational functioning in schizophrenia.

\section{Materials and Methods}

Participants. In this study, 22 schizophrenia patients (18 males) and 22 healthy control participants (16 males) were tested. Patients were recruited through the Early Diagnosis and Preventive Treatment of Psychosis clinic of the Department of Psychiatry at University of California, Davis School of Medicine. Healthy controls were recruited from the community through advertisements. All subjects provided informed consent, using a protocol approved by the Institutional Review Board at the University of California, Davis, and were compensated for participation at a rate of $\$ 25.00 / \mathrm{h}$.

All participants were native speakers of English who had not learned any other language before age 5 years, and all but three patients and two control participants were right-handed. The average age of the patient group was 24.27 years (range, 19-39 years) and 22.5 years for the control group (range, $18-37$ years); the groups did not significantly differ in age $(p=0.13)$. Patients and controls were also matched on parental education (patient group average, 15.39 years; control group average, 15.2 years; $p=0.77$ ) but, as expected because of the age of onset of the disease, differed in self-education level (patient group average, 13.02 years; control group average, 14.59 years; $p<0.05$ ). All patients had a Diagnostic and Statistical Manual of Mental Disorders, Fourth Edition (DSM-IV) diagnosis of schizophrenia or schizoaffective disorder and were on stable doses of antipsychotics at the time of testing. Control participants had no DSM-IV Axis I or Cluster A DSM-IV Axis II disorder, no first-degree relative with a psychotic disorder, and were not taking any psychotropic or cognition-enhancing medication. All participants had an estimated IQ $>70$ on the Wechsler Test of Adult Reading (Pearson Education, 2001). No participants had a head injury or neurological disease or a history of substance dependence in the past 6 months or substance abuse in the past month. All were negative on a comprehensive urine drug screen on the test day. A summary of demographic information for healthy control and patient participants, as well as clinical and functional characteristics for patients, are shown in Table 1.

Clinical and functional characteristics. Patients were assessed by clinicians using the Structured Clinical Interview for DSM-IV-TR, and the severity of clinical symptoms was rated using the 24-item Brief Psychiatric Rating Scale (BPRS) (Overall, 1974). Scales for the assessment of both positive symptoms (SAPs) and negative symptoms (SANs) (Andreasen, 1983a,b) were used to evaluate positive and negative symptom severity. A disorganization score was calculated as the sum of several measures from the BPRS (conceptual disorganization, mannerisms and posturing, dis- orientation), SANS (total score for attention), and SAPS (total score for positive formal thought disorder and bizarre behavior), following from Barch et al. (2003). Likewise, a positive score was computed using measures from the BPRS (grandiosity, suspiciousness, hallucinations, unusual thought content) and SAPS (total scores for hallucinations and delusions) and a negative score from the BPRS (emotional withdrawal, motor retardation, and blunted affect) and SANs (total scores for anhedonia/asociality, avolition, apathy, alogia, and affective flattening) (Barch et al., 2003). Community and role functioning was assessed using the Global Functioning: Role scale, and social functioning was assessed using the Global Functioning: Social scale (Cornblatt et al., 2007). Both of these are scales from 1 to 10 measuring functioning in a role and functioning socially. Finally, the Global Assessment of Functioning (GAF), a scale ranging from 1 to 100 , was additionally administered. High scores on the clinical measures (disorganization, positive, and negative) indicate greater severity of symptoms; high scores on the functional measures (role, social, and GAF) indicate higher functioning.

Stimuli. The stimuli were 72 experimental story sets, in which discourse congruence (congruent or incongruent) and lexical association (associated or unassociated) were orthogonally varied to produce four conditions (Table 2): (1) congruent-associated; (2) congruent-unassociated; (3) incongruent-associated; and (4) incongruent-unassociated. Story sets were matched across conditions for story coherence using latent semantic analysis values, which are a measure of similarity of meaning among words, sentences, or multi-sentence stories that do not necessarily pattern with propositional plausibility or coherence (Landauer et al., 1998). Congruent stories were also rated as significantly more congruent than incongruent stories, regardless of association condition. Overall story cloze probability (a measure of the predictability of the target word) was low $(<33 \%)$ and did not affect the pattern of results in two previous studies (Camblin et al., 2007; Boudewyn et al., 2012b). The critical target words were matched for length and lexical frequency across conditions. For a more detailed description of the construction and pretesting of these stimuli, see Boudewyn et al. (2012b).

The first two sentences of each passage established a discourse context, and the third (final) sentence contained the associated or unassociated target (Table 2). For example, the first story set shown in Table 2 included the locally associated prime-target pair "tables and chairs" in the third sentence to create the associated conditions, whereas the locally unassociated prime-target pair "tables and lamps" is included in the third sentence to create the unassociated conditions. In addition, target words were either congruent or incongruent with the discourse context. Using the same example at the top of Table 2, both target words (tables/lamps) are congruent when the preceding global discourse context describes rearranging furniture and are incongruent when the preceding global discourse context specifies that there would be no furniture except chairs. All except 22 of the prime and target pairs were separated by one intervening word; the remaining stimuli had either two intervening words (8) or three (14). Target words were always congruent with the meaning of the final sentence. That is, target words made sense in context if the sentence were to be heard in isolation. Story sets were divided into four lists and counterbalanced such that the critical target words and the two sentences preceding the final sentence were not repeated within subjects. Each list contained 144 experimental stories, 36 in each condition. An additional 40 filler stories were included: 20 were congruent, and 20 ended with a word that was anomalous at both the discourse and sentence level.

Story sets and fillers were spoken by a female speaker, with natural inflection and at a natural speaking rate. The words were digitally recorded using a Schoeps Mikrofone MK2 microphone and Sound Devices USBPre A/D (44,100 Hz, 16 bit). Discourse context (first two sentences of the passage) and the critical sentences were recorded separately. The onset and offset of each critical word in all conditions was determined by visual inspection of the speech waveform and by listening to the words using speech-editing software (Audacity; Soundforge). The average duration of the stories was $8951 \mathrm{~ms}$ (ranging from 7917 to $9359 \mathrm{~ms}$ ), and the average duration of the critical words was $568 \mathrm{~ms}$ (ranging from 293 to $861 \mathrm{~ms}$ ). The duration of the critical words did not differ between conditions $(t<1)$. The duration between prime and target was the same for 
Table 2. Example stimulus sets showing each of the four conditions described in text

\begin{tabular}{|c|c|c|}
\hline Condition & Context & Target sentence \\
\hline Associated congruent & $\begin{array}{l}\text { Keith was arranging furniture in the lobby of the hotel. He wanted to make sure the room appeared } \\
\text { comfortable but not overly cluttered. }\end{array}$ & $\begin{array}{l}\text { Keith was very specific about the placement of the } \\
\text { chairs and TABLES. }\end{array}$ \\
\hline Unassociated congruent & $\begin{array}{l}\text { Keith was arranging furniture in the lobby of the hotel. He wanted to make sure the room appeared } \\
\text { comfortable but not overly cluttered. }\end{array}$ & $\begin{array}{l}\text { Keith was very specific about the placement of the } \\
\text { chairs and LAMPS. }\end{array}$ \\
\hline Associated incongruent & $\begin{array}{l}\text { Keith wanted the arrangements for his outdoor wedding to be very simple. There would only be } \\
\text { seats for the guests and a simple archway. }\end{array}$ & $\begin{array}{l}\text { Keith was very specific about the placement of the } \\
\text { chairs and TABLES. }\end{array}$ \\
\hline Unassociated incongruent & $\begin{array}{l}\text { Keith wanted the arrangements for his outdoor wedding to be very simple. There would only be } \\
\text { seats for the guests and a simple archway. }\end{array}$ & $\begin{array}{l}\text { Keith was very specific about the placement of the } \\
\text { chairs and LAMPS. }\end{array}$ \\
\hline True/False & Keith was very specific about the arrangements. & \\
\hline Associated congruent & $\begin{array}{l}\text { Rick was unaware that his sister had submitted his poem in the prestigious contest. He was shocked } \\
\text { when he won the award and the hefty cash prize. }\end{array}$ & He was not prepared for the fame and FORTUNE. \\
\hline Unassociated congruent & $\begin{array}{l}\text { Rick was unaware that his sister had submitted his poem in the prestigious contest. He was shocked } \\
\text { when he won the award and the hefty cash prize. }\end{array}$ & He was not prepared for the fame and FORTUNE. \\
\hline Associated incongruent & $\begin{array}{l}\text { Rick was mortified when the videotape of his arrest was shown on the news. After the news show } \\
\text { aired, he was ridiculed by the entire neighborhood. }\end{array}$ & He was not prepared for the fame and FORTUNE. \\
\hline Unassociated incongruent & $\begin{array}{l}\text { Rick was mortified when the videotape of his arrest was shown on the news. After the news show } \\
\text { aired, he was ridiculed by the entire neighborhood. }\end{array}$ & He was not prepared for the fame and FORTUNE. \\
\hline True/False & Rick was given a public service award. & \\
\hline
\end{tabular}

For clarification, the primes are shown in italics and target words are capitalized; during the experiment, these words were not specifically emphasized.

the congruent/incongruent-associated and congruent/incongruentunassociated conditions because the same final sentence was used for the two associated conditions and the two unassociated conditions. This was accomplished by inserting a $1 \mathrm{~s}$ silence between the speech files that contained the first two context sentences and the speech files that contained the final sentences using Presentation software (Neurobehavioral Systems). (The duration of this pause was set to $1 \mathrm{~s}$ to match the average of the naturally produced pauses between sentences one and two.) There were no statistically significant differences in duration of the onset of the prime to the onset of the target between the associated and unassociated conditions $(p=0.43)$. The target sentences were the same in all conditions up to the sentence-final target word.

Comprehension questions did not focus on the prime or the target but rather on the context of the discourse (for examples, see Table 2). The same true/false question was asked in the congruent-associated/unassociated and incongruent-associated/unassociated conditions. Half of the questions required a true response, and half required a false response.

Procedure. Participants sat in a comfortable chair in an electrically shielded, sound-attenuating booth. The stimuli were presented through BeyerDynamic headphones using Presentation software. The discourse trials began with a white fixation cross at the center of the screen, $\sim 100$ $\mathrm{cm}$ in front of the participants. The fixation cross was present from 900 $\mathrm{ms}$ before onset of the stimuli and during presentation of the entire passage until the offset of the final word. The fixation cross was then replaced by a visually presented comprehension question about the preceding discourse, after $1000 \mathrm{~ms}$. Subjects were asked to make a true/false response by pressing a yes or no button with the index and middle fingers of their right hand, respectively. The comprehension question remained on the screen until the subject made a response.

Each experimental session began with a practice block consisting of filler passages, after which two of the four counterbalanced lists were presented in random order, each containing both experimental trials and fillers in a pseudorandom order. Each list was divided into four blocks for presentation purposes such that each participant listened to eight blocks of stimuli (two lists). The order of blocks was counterbalanced.

ERP recording and data reduction. EEG was recorded from 29 tin electrodes, mounted in an elastic cap (ElectroCap International). The right mastoid electrode was used as the recording reference (except for electrodes used to measure blinks and eye movements: one electrode beneath the left eye was referenced to FP1 and two placed at the outer canthi of each eye were referenced to each other). The left mastoid was also recorded for later offline algebraic re-referencing. The EEG signal was digitized online at a sampling rate of $500 \mathrm{~Hz}$, with bandpass half-amplitude cutoffs of $0.05-100 \mathrm{~Hz}$ (Neuroscan Synamp II). EEG was digitized con- tinuously along with accompanying stimulus codes used for subsequent averaging. Impedances were kept below $5 \mathrm{k} \Omega$.

Data processing and analysis were performed using the SCAN packages (Compumedics Neuroscan) and MATLAB (MathWorks) using EEGLAB toolbox (Delorme and Makeig, 2004) with the ERPLAB plugin (http://erpinfo.org/erplab), along with custom MATLAB and UNIX routines. ICA-based artifact correction was used to correct for eyeblinks. Single-trial waveforms were then screened for amplifier blocking, muscle artifacts, horizontal eye movements, and any remaining blinks over epochs of $1200 \mathrm{~ms}$, starting $200 \mathrm{~ms}$ before the onset of the critical target words. Average ERPs were computed over artifact-free trials in the four conditions. There were no differences in the average number of trials in each condition between the healthy controls (average, 30.6) and the patients (average, $30.3 ; p=0.71$ ). All ERPs were filtered offline with a Gaussian low-pass filter with a $25 \mathrm{~Hz}$ half-amplitude cutoff. Statistical analyses were conducted on the filtered data.

\section{Results}

\section{Behavior}

Accuracy on the true/false comprehension showed a main effect of group. Patients, on average, scored $85 \%$ correct on the true/ false comprehension questions, whereas controls were slightly but significantly more accurate on average (89\%; $p<0.05)$. There were no effects of either global discourse congruence or local lexical association on performance, nor any interactions of these factors with group ( $p$ values $>0.12$ ), with patients scoring $86,85,84$, and $85 \%$ compared with $91,90,90$, and $88 \%$ for the congruent/associated, incongruent/associated, congruent/unassociated, and incongruent/unassociated conditions, respectively. This pattern of a general deficit in performance but no differential deficits for the patients relative to controls was an expected outcome, because the questions in this study were always about the discourse that was heard before the critical manipulations occurred (i.e., before the prime and target words of the final sentence of the discourse). Nevertheless, we included these questions to encourage participants to engage in comprehension when they heard the stories.

\section{ERPs}

ERP waveforms comparing all four conditions are shown in Figure $1 a$ for the control group and Figure $1 b$ for the patient group. 


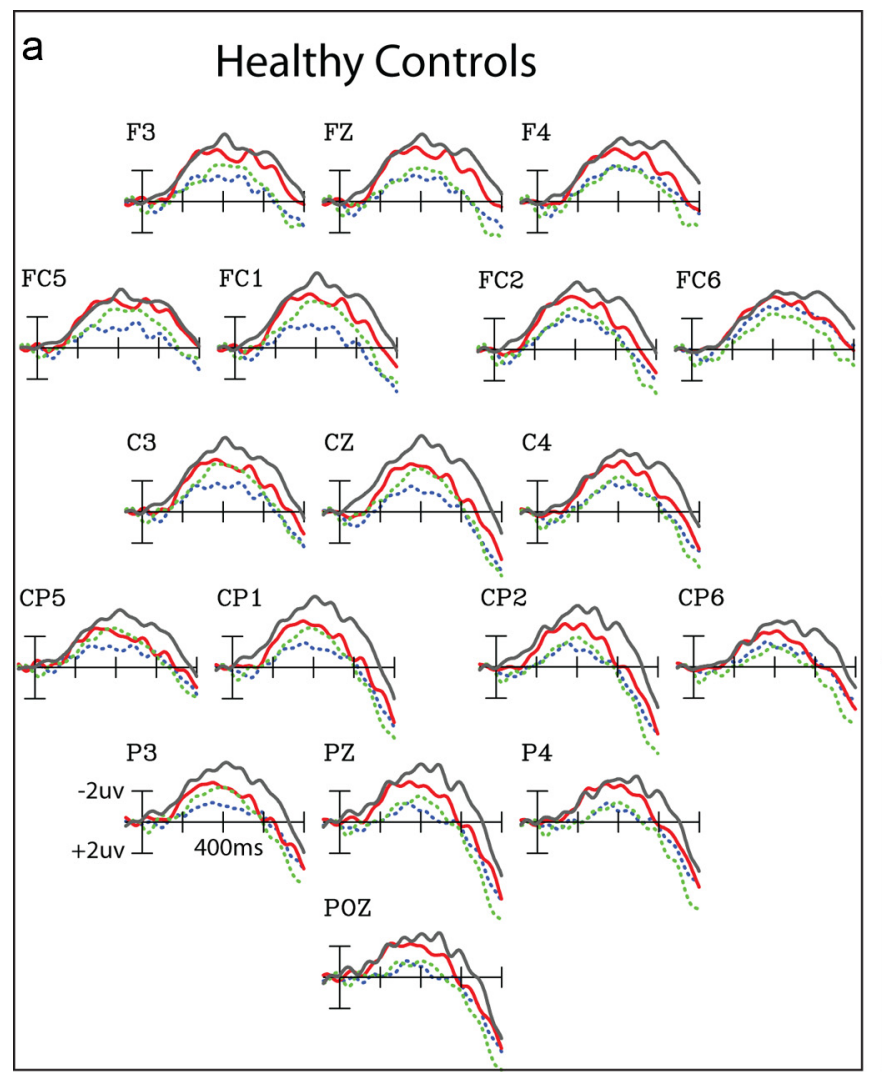

\section{b Schizophrenia Patients}
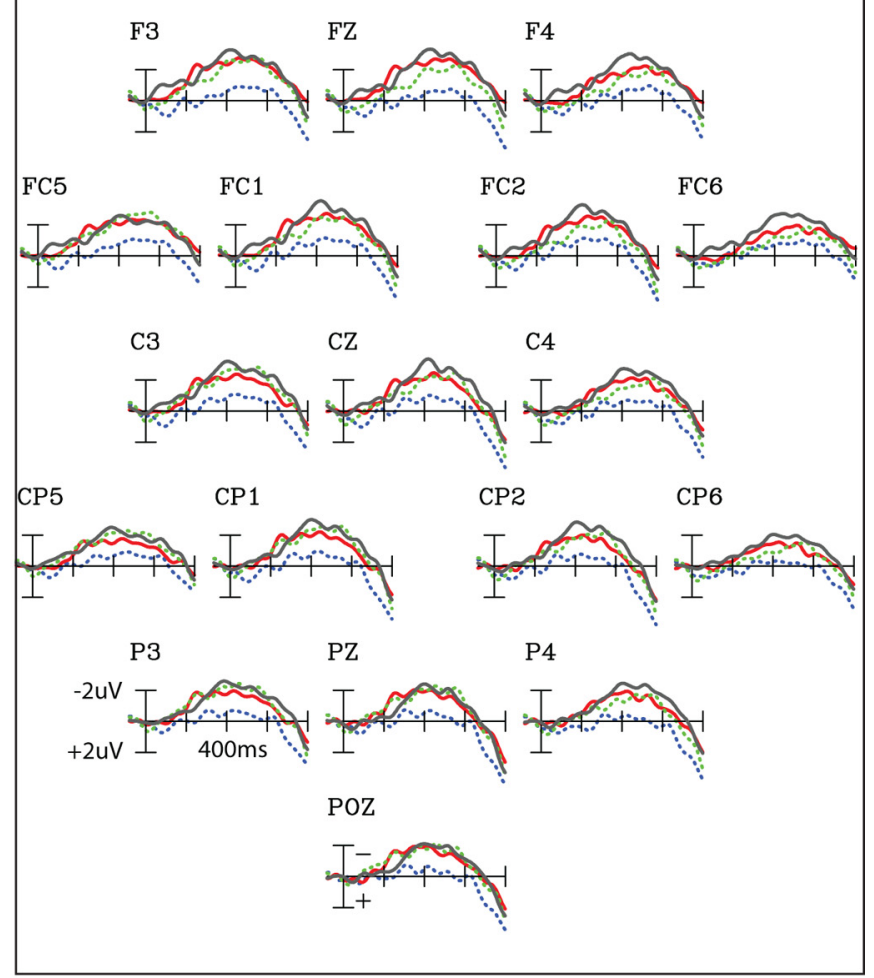

\section{$\begin{array}{cl}\longleftarrow & \begin{array}{l}\text { Incongruent Unassociated } \\ \text { Congruent Unassociated } \\ \ldots . . .\end{array} \\ \text { Incongruent Associated } \\ \ldots . . . . & \text { Congruent Associated }\end{array}$}

Figure 1. $\quad \boldsymbol{a}, \boldsymbol{b}$, Displayed are ERP waveforms comparing the four conditions: (1) congruent associated (blue dotted); (2) congruent unassociated (red solid); (3) incongruent associated (green dotted); and (4) incongruent unassociated (gray solid). $\boldsymbol{a}$ shows the results for the control group, and $\boldsymbol{b}$ shows the results for the schizophrenia group. The vertical axis depicts the amplitude in microvolts $(\mu \mathrm{V})$. Negative voltage is plotted up. The horizontal axis depicts the the time in milliseconds (ms). Each tick mark is $200 \mathrm{~ms}$.

Topographic maps showing the distribution of the effects across all four pairwise comparisons and time windows are shown in Figure 2 for the control group and in Figure 3 for the patient group.

The omnibus by-groups repeated-measures ANOVA (rANOVA) showed significant three-way interactions of group $\times$ global discourse congruence $\times$ local association. Follow-up analyses revealed interactions of global discourse congruence $\times$ local association in both the patient and control groups; these were followed up with pairwise analyses that revealed distinct patterns of effects for the control group compared with the patient group. In short, the control group showed robust effects of local association as well as global discourse congruence; in contrast, the patient group showed significant effects of local association but only showed effects of global discourse congruence when target words were also locally associated. In other words, the global discourse effects in the patient group were dependent on the presence of the local prime word in the associated conditions. These results are described in more detail below and are interpreted in Discussion.

\section{Group analyses}

Main ANOVAs

Three rANOVAs were conducted on the mean amplitude of the N400 in the 350-650 ms epoch, at midline, medial, and lateral electrode sites (based on previous studies; Kuperberg et al., 2010, 2011). Discourse congruence (congruent, incongruent), local as- sociation (associated, unassociated), and electrode site $(\mathrm{Fz}, \mathrm{Cz}$, $\mathrm{Pz}, \mathrm{POz}$ ) were included as within-subjects factors in the midline analysis, and group (schizophrenia patients, healthy controls) was included as a between-subjects factor. For the medial (electrodes FC1, FC2, C3, C4, CP1, CP2) and lateral (electrodes F3, F4, FC5, FC6, CP5, CP6, P3, P4) analyses, two within-subjects topographic factors were included instead of electrode site: (1) hemisphere (left, right); and (2) anteriority (medial: fronto-central, centro-parietal, parietal; lateral: frontal, fronto-central, centroparietal, parietal). A Greenhouse-Geisser correction was applied to $F$ tests with more than one degree of freedom in the numerator for all relevant analyses in this study. The results of these omnibus group-level analyses are reported in Table 3.

The ANOVA for midline sites revealed significant main effects of discourse congruence $\left(F_{(1,42)}=13.68 ; p<0.001\right)$ and local association $\left(F_{(1,42)}=23.93 ; p<0.001\right)$ and a significant group $\times$ discourse congruence $\times$ local association interaction $\left(F_{(1,42)}=\right.$ $4.35 ; p<0.05)$. There were no significant interactions by electrode site in this analysis.

The medial analysis also showed significant main effects of discourse congruence $\left(F_{(1,42)}=12.07 ; p<0.01\right)$ and local association $\left(F_{(1,42)}=19.65 ; p<0.001\right)$ and a significant group $\times$ discourse congruence $\times$ local association interaction $\left(F_{(1,42)}=\right.$ $4.25 ; p<0.05)$. There was also a trend toward an interaction of group $\times$ congruence $\times$ hemisphere $\times$ anteriority $\left(F_{(2,84)}=2.61\right.$; 

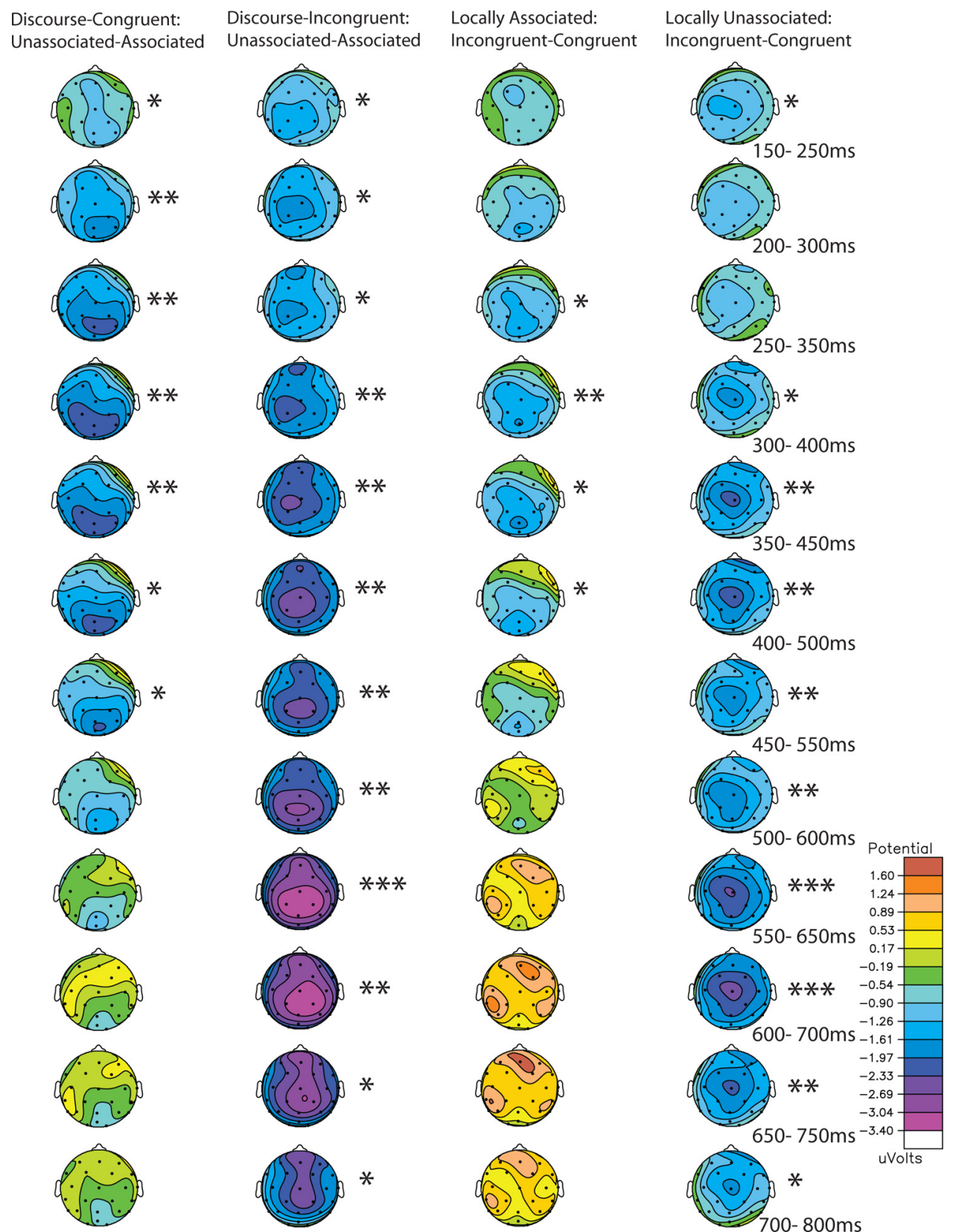

Figure 2. Topographic maps showing the scalp distribution of the N400 effects for the four pairwise comparisons in 100 ms epochs from 150 to 800 ms for the control group. ${ }^{*} p<0.05$, ${ }^{* *} p<$ $0.001,{ }^{* * *} p<0.001$.

$p<0.08)$ and marginal interaction of local association $\times$ hemisphere $\times$ anteriority $\left(F_{(2,84)}=3 ; p<0.06\right)$.

Finally, the lateral analysis also revealed significant main effects of discourse congruence $\left(F_{(1,42)}=8.96 ; p<0.01\right)$ and local association $\left(F_{(1,42)}=17.91 ; p<0.001\right)$ and a significant group $\times$ discourse congruence $\times$ local association interaction $\left(F_{(1,42)}=\right.$ $4.56 ; p<0.05)$. Additionally, there were significant interactions of discourse congruence $\times$ local association $\times$ hemisphere $\left(F_{(2,84)}=5.19 ; p<0.05\right)$, group $\times$ hemisphere $\times$ anteriority $\left(F_{(3,126)}=5.32 ; p<0.001\right)$, local association $\times$ hemisphere $\times$ anteriority $\left(F_{(3,126)}=3.33 ; p<0.05\right)$, and discourse congruence $\times$ local association $\times$ hemisphere $\times$ anteriority $\left(F_{(3,126)}=\right.$ 5.67; $p<0.01)$.

Time course analyses

To determine the onset and duration of these effects (as in the study by Boudewyn et al., 2012b), we performed analyses in 100 ms epochs between 150 and $800 \mathrm{~ms}$, with an overlap of $50 \mathrm{~ms}$ between consecutive windows (150-250, 200-300, 250-350, $300-400,350-450,400-500,450-550,500-600,650-750$, and $700-800 \mathrm{~ms})$. These analyses revealed robust and long-lasting main effects of discourse congruence from $\sim 250$ to $750 \mathrm{~ms}(p<$ $0.05)$ and of local association throughout all time windows (150$800 \mathrm{~ms} ; p<0.05)$; these effects were further characterized by group $\times$ discourse congruence $\times$ local association interactions in all windows except between 250 and $500 \mathrm{~ms}$.

Pairwise analyses

Motivated by our a priori predictions and the significant grouplevel interactions found in the analyses above involving group, discourse congruence, local association, and scalp distribution (electrode, hemisphere, and anteriority), we conducted pairwise comparisons for the two groups separately, across the same electrode configurations (midline, medial, lateral) and overlapping 


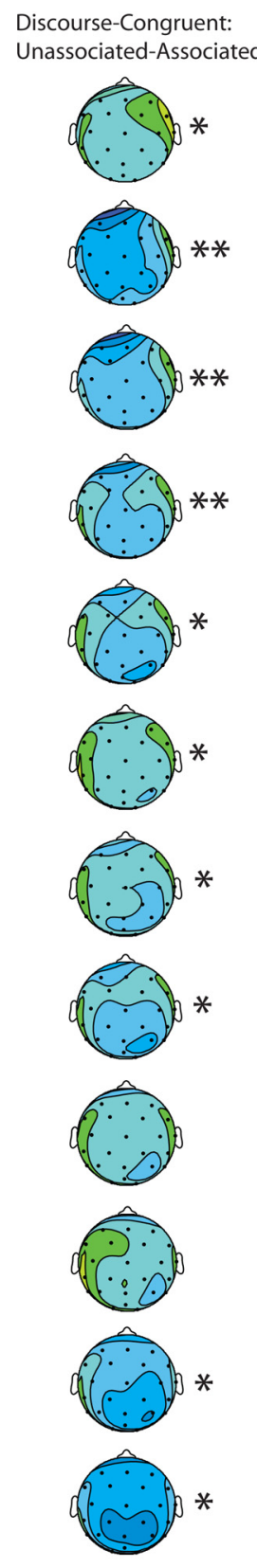

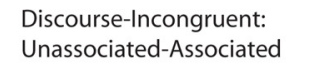

Locally Associated:

Incongruent-Congruent
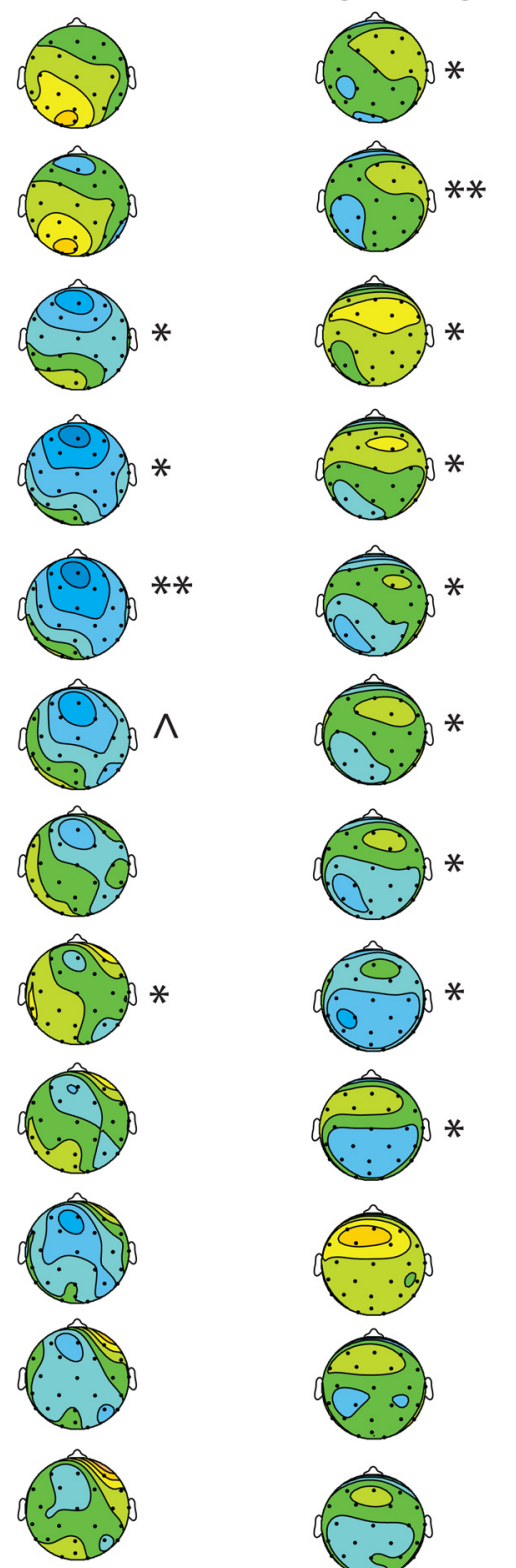

Locally Unassociated:

Incongruent-Congruent

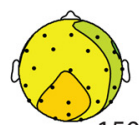

$150-250 \mathrm{~ms}$

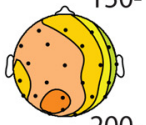

$200-300 \mathrm{~ms}$

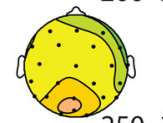

$250-350 \mathrm{~ms}$
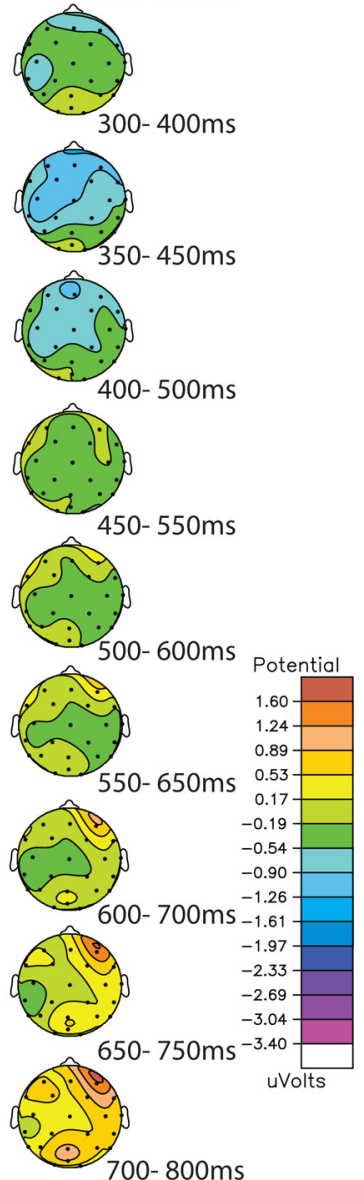

Figure 3. Topographic maps showing the scalp distribution of the $\mathrm{N} 400$ effects for the four pairwise comparisons in $100 \mathrm{~ms}$ epochs from 150 to 800 ms for the patient group. ${ }^{*} p<0.05{ }^{* *} p<$ $0.001,{ }^{* * *} p<0.001, \wedge p<0.07$.

Table 3. Results of omnibus repeated-measures ANOVA in the N400 time window

\begin{tabular}{lllllll}
\hline Analysis & $\begin{array}{l}\text { Global } \\
\text { congruence }\end{array}$ & $\begin{array}{l}\text { Global congruence } \times \\
\text { group }\end{array}$ & $\begin{array}{l}\text { Local } \\
\text { association }\end{array}$ & $\begin{array}{l}\text { Local association } \times \\
\text { group }\end{array}$ & $\begin{array}{l}\text { Global congruence } \times \\
\text { local association }\end{array}$ & $\begin{array}{l}\text { Global congruence } \times \text { local } \\
\text { association } \times \text { group }\end{array}$ \\
\hline Midline & $13.68^{* * *}$ & $<1$ & $23.93^{* * *}$ & 1.4 & $<1$ & $4.35^{*}$ \\
Medial & $12.07^{* *}$ & $<1$ & $19.65^{* * *}$ & $<1$ & $<1$ & $4.25^{*}$ \\
Lateral & $8.96^{* *}$ & $<1$ & $17.91^{* * *}$ & $<1$ & $<1$ & $4.56^{*}$
\end{tabular}

Degrees of freedom for all $F$ values were $(1,42)$. Interactions with scalp distribution (electrode site, hemisphere, anteriority) are reported in Materials and Methods. ${ }^{*} p<0.05,{ }^{* *} p<0.01$, ${ }^{* * *} p<0.001$.

$100 \mathrm{~ms}$ time windows. These analyses enabled us to identify the source of the interactions and establish the pattern of results for each group; results are summarized in Figures 2 and 3 and described below.

For healthy controls, a significant effect of discourse congruence (reduced amplitude for congruent compared with incongruent targets) for locally associated words was found in all time windows between 300 and $500 \mathrm{~ms}$ at midline sites and between 250 and $500 \mathrm{~ms}$ at medial sites but did not reach significance at lateral sites. For the schizophrenia patients, the effects of discourse congruence for locally associated words had an earlier onset and lasted longer: significant effects were found in all time windows between 200 and $300 \mathrm{~ms}$, between 350 and $600 \mathrm{~ms}$ for midline sites, and between 150 and $550 \mathrm{~ms}$ for medial sites. In 
contrast to controls, this effect was also significant at lateral electrode sites between 150 and $600 \mathrm{~ms}$.

The control group showed a significant effect of discourse congruence (reduced amplitude for congruent compared with incongruent targets) for locally unassociated words in all time windows between 300 and $800 \mathrm{~ms}$ at midline sites, between 150 and $250 \mathrm{~ms}$ and 300 and $800 \mathrm{~ms}$ at medial sites, and between 350 and $750 \mathrm{~ms}$ at lateral sites. In contrast, schizophrenia patients showed no significant effect of discourse congruence for locally unassociated words for any of the analyses.

Significant effects of local association (reduced amplitude for associated compared with unassociated targets) for discoursecongruent words were found in the control group in all time windows between 150 and $550 \mathrm{~ms}$ at midline sites, between 150 and $500 \mathrm{~ms}$ at medial sites, and between 150 and $450 \mathrm{~ms}$ at lateral sites. For the schizophrenia group, significant effects of local association (reduced amplitude for associated compared with unassociated targets) for discourse-congruent words lasted longer and were found in all time windows between 150 and $600 \mathrm{~ms}$ and 700 and $800 \mathrm{~ms}$ for midline sites, between 150 and $550 \mathrm{~ms}$ and 700 and $800 \mathrm{~ms}$ for medial sites, and between 150 and $550 \mathrm{~ms}$ and 650 and $800 \mathrm{~ms}$ at lateral sites.

For healthy controls, significant effects of local association (reduced amplitude for associated compared with unassociated targets) for discourse-incongruent words were found in all time windows between 150 and $800 \mathrm{~ms}$ at midline sites, between 150 and $800 \mathrm{~ms}$ at medial sites, and between 150 and $800 \mathrm{~ms}$ at lateral sites. For the schizophrenia group, the effects of local association (reduced amplitude for associated compared with unassociated targets) for discourse-incongruent words were restricted to a more limited epoch: significant effects were found in all time windows between 250 and $350 \mathrm{~ms}$ and 350 and $450 \mathrm{~ms}$ for midline sites, between 300 and $450 \mathrm{~ms}$ for medial sites, and between 300 and $450 \mathrm{~ms}$ at lateral sites.

\section{Correlations with clinical and functional measures}

To test the hypothesis that the magnitude of ERP effects of lexical association and discourse congruence would be linked with clinical characteristics of schizophrenia patients, we conducted a series of correlation analyses. All the correlational analyses were planned comparisons, based on the approach adopted by previous studies (Yoon et al., 2008). We had two main predictions: (1) that our ERP results would correlate with functional measures (GAF) and (2) that they would correlate with disorganization. We found that ERP effects of local association (i.e., mean amplitude to associated targets subtracted from mean amplitude to unassociated targets) were significantly correlated with GAF, such that local association effects tended to be larger for individuals with lower GAF scores from 450 to $650 \mathrm{~ms}$ (Table 4).

In the pairwise comparisons (Tables 5, 6), increased ERP effects of local association for discourse-congruent words (unassociated/congruent minus associated/congruent) were associated with lower GAF scores from 450 to $800 \mathrm{~ms}$. In addition, increased ERP effects of local association for discourse-incongruent words (i.e., unassociated/incongruent minus associated/incongruent) were associated with increased GAF scores from 300 to $400 \mathrm{~ms}$. Finally, increased effects of discourse congruence for locally unassociated words (congruent/unassociated minus incongruent/ unassociated) were associated with higher GAF scores in the 600$700 \mathrm{~ms}$ epoch.

Thus, our results showed a significant correlation with GAF but not with disorganization. This latter result may reflect the fact that the clinically stable outpatients in this sample had relatively
Table 4. Correlation values for GAF and main effects of association (left: unassociated-associated) and congruence (right: incongruent- congruent)

\begin{tabular}{lll}
\hline & \multicolumn{2}{l}{$\begin{array}{l}\text { Correlations of clinical and functional characteristics } \\
\text { with main ERP effects }\end{array}$} \\
\cline { 2 - 3 } Duration (ms) & Association & Discourse congruence \\
\hline $150-250$ & -0.059 & 0.182 \\
$200-300$ & -0.127 & 0.013 \\
$250-350$ & -0.256 & -0.243 \\
$300-400$ & -0.129 & -0.131 \\
$350-450$ & 0.263 & -0.118 \\
$400-500$ & 0.328 & -0.257 \\
$450-550$ & $0.451^{*}$ & -0.237 \\
$500-600$ & $0.468^{*}$ & -0.143 \\
$550-650$ & $0.46^{*}$ & -0.136 \\
$600-700$ & 0.337 & -0.189 \\
$650-750$ & 0.273 & -0.118 \\
$700-800$ & 0.307 & -0.17 \\
\hline
\end{tabular}

$n=22 .{ }^{*}$ indicates significant correlations. For interpretation, see Results.

Table 5. Correlation values for GAF and effects of association (left: unassociatedassociated for congruent contexts only; right: unassociated-associated for incongruent contexts only)

\begin{tabular}{llc}
\hline & $\begin{array}{l}\text { Correlations of clinical and functional characteristics with } \\
\text { effects of local association } \\
\text { associated) }\end{array}$ \\
\cline { 2 - 3 } Duration (ms) & Globally congruent & Globally incongruent \\
\hline $150-250$ & -0.099 & 0.024 \\
$200-300$ & 0.033 & -0.284 \\
$250-350$ & -0.062 & -0.378 \\
$300-400$ & 0.176 & $-0.429^{*}$ \\
$350-450$ & 0.263 & -0.278 \\
$400-500$ & 0.328 & 0.245 \\
$450-550$ & $0.426^{*}$ & 0.325 \\
$500-600$ & $0.501^{*}$ & 0.066 \\
$550-650$ & $0.566^{* *}$ & 0.004 \\
$600-700$ & $0.492^{*}$ & -0.034 \\
$650-750$ & $0.449^{*}$ & -0.142 \\
$700-800$ & $0.466^{*}$ & -0.155 \\
\hline
\end{tabular}

$n=22 .{ }^{*}$ and ${ }^{*}$ indicate significant correlations. For interpretation, see Results.

Table 6. Correlation values for GAF and effects of congruence (left: incongruentcongruent for associated words only; right: incongruent- congruent for unassociated words only)

Correlations of clinical and functional characteristics with effects of global congruence (discourse: incongruentcongruent)

\begin{tabular}{lcc}
\cline { 2 - 3 } Duration (ms) & Locally associated & Locally unassociated \\
\hline $150-250$ & 0.084 & 0.229 \\
$200-300$ & 0.133 & -0.114 \\
$250-350$ & -0.101 & -0.305 \\
$300-400$ & -0.322 & -0.322 \\
$350-450$ & 0.123 & -0.331 \\
$400-500$ & -0.133 & -0.299 \\
$450-550$ & -0.084 & -0.312 \\
$500-600$ & 0.145 & -0.366 \\
$550-650$ & 0.176 & -0.386 \\
$600-700$ & 0.113 & $-0.424^{*}$ \\
$650-750$ & 0.213 & -0.376 \\
$700-800$ & 0.168 & -0.394 \\
\hline
\end{tabular}

$n=22 .{ }^{*}$ indicates significant correlations. For interpretation, see Results.

low levels of disorganization. To examine in more detail the effects of clinical and disorganization symptoms, we further examined correlations between our ERP results and positive and negative symptoms, and this did not lead to significant results. 


\section{Discussion}

In the current study, we aimed to increase our understanding of the cognitive and neural systems underlying deficits in language comprehension in schizophrenia. We assessed the ability of schizophrenia patients to use global discourse context and local lexical context (associations) during the online comprehension of auditory discourse. We predicted that, in contrast to controls, deficits in the ability to maintain context-relevant information in schizophrenia would lead to deficits in global discourse comprehension. Importantly, we additionally predicted that the ability to benefit from local lexical context would be intact in schizophrenia. The presence of lexical association effects in the schizophrenia group coupled with a lack of discourse congruence effects indicates that the basic processing of words was intact, consistent with a specific deficit in higher-level cognitive control systems. The results revealed significant effects of both lexical associations and global discourse congruence in healthy control subjects. The pattern of results in the schizophrenia group was more complex: patients showed intact effects of lexical association regardless of whether the target words appeared in congruent or incongruent discourse contexts, but the patient group only showed discourse congruence effects for target words that were also associated. In other words, patients were always sensitive to the presence of local lexical associations and were additionally sensitive to whether or not incoming words fit well with the preceding global context, provided that local lexical associations were present. In contrast to healthy controls, when target words were locally unassociated, patients did not show effects of discourse congruence.

This pattern of results in the schizophrenia patients is particularly interesting given that we found sensitivity to discourselevel semantic fit in the associated condition, indicating that, under some circumstances, patients are able to benefit from global discourse context. This may appear to contradict results of previous studies that have shown deficits at the discourse level in schizophrenia (Levy and Maxwell, 1968; Maher et al., 1980; Manschreck et al., 1991; Ditman and Kuperberg, 2007; Ditman and Kuperberg, 2010). However, the schizophrenia patients in the present study may only have shown impaired discourse processing in one of the conditions for two reasons. First, previous studies have focused on relatively taxing manipulations (e.g., inference generation) compared with the condition in which patients showed intact discourse effects in the present study. Second, the main task of the participants was to listen for comprehension without imposing demands of a secondary task as they were processing the spoken input. Importantly, however, task demands were equally low for both congruent and incongruent conditions up to the point of the target word in the associated compared with the unassociated condition. In the associated condition, intact discourse effects were found in patients. In contrast, in the unassociated condition, when demands were higher, patients showed deficits compared with controls. Thus, the findings of the present study are not inconsistent with previous work in that we see discourse deficits when demands are relatively high, i.e., in our study, when the global discourse context is not cued by associated words in the local context.

Kuperberg et al. (2010b) have argued that differences in the N400 effects between schizophrenia patients and normal control participants are typically maximal at the sentence-final word position because of sentence final evaluation and wrap-up effects needed for sentence interpretation. The integration demands for discourse final words are typically greater than for sentences, because the overall meaning of the multi-sentence discourse has to be activated and integrated. In the present study, these demands were further enhanced because of the fleeting nature of the speech signal, requiring listeners to distribute cognitive resources between attending to the final word and activating the discourse context. This process was maximally demanding when there was no local cue from an associated word that could boost the activation of the global discourse representation, and indeed the patients did not show any effects of discourse congruence in the unassociated condition. Thus, the results of this study indicate that discourse representations in schizophrenia needed a boost from a local cue to be able to fully integrate the discourse meaning at the discourse-final word. When this cue was missing, the patients did not immediately notice that a critical word was inconsistent with the meaning of the discourse. We suggest that this is attributable to a reduced ability to control the maintenance of discourse information, leading to a less stable representation of the discourse.

In addition, we found significant correlations between the size of the ERP effects of association and measures of social functioning (GAF) in schizophrenia patients, such that larger ERP effects of local association were correlated with reduced social functioning. This is consistent with our hypothesis that more severely impaired individuals rely to a greater extent on local word associations. The direction of the correlations for the two types of local association effects (for words that were also globally congruent vs incongruent) further characterized this relationship: increased ERP effects of local association for words that were also globally incongruent were associated with better functioning (as measured by GAF), whereas increased ERP effects of local association for words that were locally congruent were linked to poorer functioning (as measured by GAF). In other words, when comparing locally associated with unassociated words that were embedded in congruent discourse (i.e., under the least controldemanding circumstances), more impaired patients tended to show the largest local association effects. In contrast, when comparing locally associated with unassociated words that were also discourse incongruent (i.e., under more control-demanding circumstances), the better functioning patients tended to show the largest association effects. In addition, increased ERP effects of global congruence for words that were locally unassociated (i.e., the most control-demanding circumstances) were associated with better functioning in patients (as measured by GAF). Although this effect did not reach significance in the patient group as a whole, the significant correlation with GAF indicates that the higher functioning patients were more likely to be able to discriminate between globally congruent and incongruent discourse in the locally unassociated condition, indicating relatively higher levels of discourse comprehension and use of control. These findings suggest an intriguing and novel mechanism by which cognitive control deficits may have their widely demonstrated impact on social and role functioning in schizophrenia, mediated through their effects on language comprehension, which is such an essential element of human communication and social interactions.

The pattern of results in schizophrenia patients-spared local association effects but impaired discourse comprehension when not supported by local associations among meanings of wordscannot be explained by a generalized low-level deficit in basic auditory or language processing for several reasons. First, the patients in this study showed earlier effects of priming as a function of local association than did control participants. A perceptual processing deficit would predict later-than-normal effects of priming, because perceptual difficulties would most likely result 
in reduced or later activation of word meanings. In addition, our findings are not consistent with generalized low-level cognitive deficits, because we show spared local language processing and intact global message comprehension when discourse comprehension was supported by local associations among words in the context.

Therefore, we propose that the very specific discourse comprehension deficit observed in the present study is mediated by deficits in prefrontal control in these patients. Several fMRI studies of language comprehension in unimpaired controls show increased activity in the dorsolateral prefrontal cortex (DLPFC) when contextual integration is especially demanding (Kaan and Swaab, 2002; Novais-Santos et al., 2007; Ferstl et al., 2008; Kuperberg et al., 2008a; Hoenig and Scheef, 2009), for example, when suppression of the contextually inappropriate dominant meaning of an ambiguous word is required (Novais-Santos et al., 2008; Hoenig and Scheef, 2009). This proposal of a deficit in prefrontal control in schizophrenia is also consistent with findings showing a direct relationship between hypofrontality in the DLPFC and impaired conflict control in schizophrenia (Minzenberg et al., 2009; Lesh et al., 2011). It is further supported by fMRI findings by Kuperberg et al. (2008a), who observed that impairments in sentence comprehension in schizophrenia patients may be directly related to abnormal functioning of the DLPFC. In this study, schizophrenia patients and controls showed relatively similar activation patterns during sentence processing in lateral temporal cortices and the inferior frontal gyrus (IFG), whereas increases in integration demands resulted in greater activation of DLPFC in healthy controls but not in patients with schizophrenia. In contrast, Kuperberg et al. (2007) observed increased temporal and IFG activations in response to semantic priming among individual words in schizophrenia patients.

In summary, these results suggest that patients with schizophrenia have difficulties with discourse comprehension, when control demands are increased in the absence of local associations that can cue the activation of the discourse representation. These results are consistent with a role for more general cognitive control problems in the language comprehension deficits in schizophrenia and implicate functional neural systems involving the prefrontal cortex in the socially disabling communication deficits that are present in this illness.

\section{References}

Andreasen NC (1983a) The scale for the assessment of negative symptoms (SANs). Iowa City, IA: University of Iowa.

Andreasen NC (1983b) The scale for the assessment of positive symptoms (SAPS). Iowa City, IA: University of Iowa.

Barch DM, Cohen JD, Servan-Schreiber D, Steingard S, Cohen JD, Steinhauer SS, van Kammen DP (1996) Semantic priming in schizophrenia: an examination of spreading activation using word pronunciation and multiple SOAs. J Abnorm Psychol 105:592-601. CrossRef Medline

Barch DM, Carter CS, MacDonald AW 3rd, Braver TS, Cohen JD (2003) Context-processing deficits in schizophrenia: diagnostic specificity, 4-week course, and relationships to clinical symptoms. J Abnorm Psychol 112:132-143. CrossRef Medline

Boudewyn MA, Carter CS, Swaab TY (2012a) Cognitive control and discourse comprehension in schizophrenia. Schizophr Res Treatment 2012: 484502. CrossRef Medline

Boudewyn MA, Gordon PC, Long D, Polse L, Swaab TY (2012b) Does discourse congruence influence spoken language comprehension before lexical association? Evidence from event-related potentials. Lang Cogn Process 27:698-733. CrossRef Medline

Boudewyn MA, Long DL, Swaab TY (2012c) Cognitive control influences the use of meaning relations during spoken language comprehension. Neuropsychologia 50:2659-2668. CrossRef Medline

Camblin CC, Gordon PC, Swaab TY (2007) The interplay of discourse con- gruence and lexical association during sentence processing: evidence from ERPs and eye tracking. J Mem Lang 56:103-128. CrossRef Medline

Cohen JD, Barch DM, Carter C, Servan-Schreiber D (1999) Contextprocessing deficits in schizophrenia: converging evidence from three theoretically motivated cognitive tasks. J Abnorm Psychol 108:120-133. CrossRef Medline

Cornblatt BA, Auther AM, Niendam T, Smith CW, Zinberg J, Bearden CE, Cannon TD (2007) Preliminary findings for two new measures of social and role functioning in the prodromal phase of schizophrenia. Schizophr Bull 33:688-702. CrossRef Medline

Delorme A, Makeig S (2004) EEGLAB: an open source toolbox for analysis of single-trial EEG dynamics including independent component analysis. J Neurosci Methods 134:9-21. CrossRef Medline

Ditman T, Kuperberg GR (2007) The time course of building discourse coherence in schizophrenia: an ERP investigation. Psychophysiology 44: 991-1001. CrossRef Medline

Ditman T, Kuperberg GR (2010) Building coherence: a framework for exploring the breakdown of links across clause boundaries in schizophrenia. J Neurolinguistics 23:254-269. CrossRef Medline

Ditman T, Goff D, Kuperberg GR (2011) Slow and steady: sustained effects of lexico-semantic associations can mediate referential impairments in schizophrenia. Cogn Affect Behav Neurosci 11:245-258. CrossRef Medline

Docherty NM, Rhinewine JP, Labhart RP, Gordinier SW (1998) Communication disturbances and family psychiatric history in parents of schizophrenic patients. J Nerv Ment Dis 186:761-768. Medline

Ferstl EC, Neumann J, Bogler C, von Cramon DY (2008) The extended language network: a meta-analysis of neuroimaging studies of text comprehension. Hum Brain Mapp 29:581-593. CrossRef Medline

Gernsbacher MA, Tellent KA, Bollinger CM (1999) Disordered discourse in schizophrenia described by the structure building framework. Discourse Studies 1:355-372. CrossRef

Hoenig K, Scheef L (2009) Neural correlates of semantic ambiguity processing during context verification. Neuroimage 45:1009-1019. CrossRef Medline

Hoffman RE, Stopek S, Andreasen NC (1986) A comparative study of manic vs schizophrenic speech disorganization. Arch Gen Psychiatry 43:831838. CrossRef Medline

Kaan E, Swaab TY (2002) The brain circuitry of syntactic comprehension. Trends Cogn Sci 6:350-356. CrossRef Medline

Kreher DA, Goff D, Kuperberg GR (2009) Why all the confusion? Experimental task explains discrepant semantic priming effects in schizophrenia under "automatic" conditions: evidence from event-related potentials. Schizophr Res 111:174-181. CrossRef Medline

Kuperberg GR (2010a) Language in schizophrenia part 1: an introduction. Lang Linguist Compass 4:576-589. CrossRef Medline

Kuperberg GR (2010b) Language in schizophrenia part 2: what can psycholinguistics bring to schizophrenia... and vice versa? Lang Linguist Compass 4:590-604. CrossRef Medline

Kuperberg GR, Deckersbach T, Holt DJ, Goff D, West WC (2007) Increased temporal and prefrontal activity in response to semantic associations in schizophrenia. Arch Gen Psychiatry 64:138-151. CrossRef Medline

Kuperberg GR, West WC, Lakshmanan BM, Goff D (2008a) Functional magnetic resonance imaging reveals neuroanatomical dissociations during semantic integration in schizophrenia. Biol Psychiatry 64:407-418. Medline

Kuperberg GR, Sitnikova T, Lakshmanan BM (2008b) Neuroanatomical distinctions within the semantic system during sentence comprehension: evidence from functional magnetic resonance imaging. Neuroimage 40: 367-388. CrossRef Medline

Kuperberg GR, Kreher DA, Ditman T (2010) What can event-related potentials tell us about language, and perhaps even thought, in schizophrenia? Int J Psychophysiol 75:66-76. CrossRef Medline

Kuperberg GR, Paczynski M, Ditman T (2011) Establishing causal coherence across sentences: an ERP study. J Cogn Neurosci 23:1230-1246. CrossRef Medline

Landauer TK, Foltz PW, Laham D (1998) An introduction to latent semantic analysis. Discourse Processes 25:259-284. CrossRef

Lesh TA, Niendam TA, Minzenberg MJ, Carter CS (2011) Cognitive control deficits in schizophrenia: mechanisms and meaning. Neuropsychopharmocology 201:316-338.

Levy R, Maxwell AE (1968) The effect of verbal context on the recall of 
schizophrenics and other psychiatric patients. Br J Psychiatry 114:311316. CrossRef Medline

MacDonald AW 3rd, Carter CS, Kerns JG, Ursu S, Barch DM, Holmes AJ, Stenger VA, Cohen JD (2005) Specificity of prefrontal dysfunction and context processing deficits to schizophrenia in never-medicated patients with first-episode psychosis. Am J Psychiatry 162:475-484. CrossRef Medline

Maher BA, Manschreck TC, Rucklos ME (1980) Contextual constraint and the recall of verbal material in schizophrenia: the effect of thought disorder. Br J Psychiatry 137:69-73. CrossRef Medline

Manschreck TC, Maher BA, Milavetz JJ, Ames D, Weisstein CC, Schneyer ML (1988) Semantic priming in thought disordered schizophrenic patients. Schizophr Res 1:61-66. CrossRef Medline

Manschreck TC, Maher BA, Rosenthal JE, Berner J (1991) Reduced primacy and related features in schizophrenia. Schizophr Res 5:35-41. CrossRef Medline

Minzenberg MJ, Laird AR, Thelen S, Carter CS, Glahn DC (2009) Metaanalysis of 41 functional neuroimaging studies of executive function in schizophrenia. Arch Gen Psychiatry 66:811-822. CrossRef Medline

Novais-Santos S, Gee J, Shah M, Troiani V, Work M, Grossman M (2007)
Resolving sentence ambiguity with planning and working memory resources: evidence from fMRI. Neuroimage 37:361-378. CrossRef Medline

Overall JE (1974) The brief psychiatric rating scale in psychopharmacology research. In: Psychological measurements in psychopharmacology: modern problems in pharmacopsychiatry (Picho P, ed), pp 67-78. Paris: Karger.

Pearson Education (2001) Wechsler Test of Adult Reading. New York: Pearson.

Spitzer M, Braun U, Hermle L, Maier S (1993) Associative semantic network dysfunction in thought-disordered schizophrenic patients: direct evidence from indirect semantic priming. Biol Psychiatry 15:864-877. Medline

Swaab TY, Ledoux K, Camblin CC, and Boudewyn M (2012) ERPs and language processing. In: Oxford handbook of event-related potential components, Chap 14 (Luck SJ, Kappenman ES, ed), pp 397-440. New York: Oxford UP.

Yoon JH, Minzenberg MJ, Ursu S, Ryan Walter BS, Walters R, Wendelken C, Ragland JD, Carter CS (2008) Association of dorsolateral prefrontal cortex dysfunction with disrupted coordinated brain activity in schizophrenia: relationship with impaired cognition, behavioral disorganization, and global function. Am J Psychiatry 165:1006-1014. CrossRef Medline 